\title{
CIRCULAÇÃO \\ DE DISCURSOS \\ DE ÓDIO ONLINE \\ CONTRA REFUGIADOS: \\ ENTEXTUALIZAÇÃO, \\ INDEXICALIDADE E \\ INTELIGIBILIDADE
}

\section{CIRCULACIÓN DEL DISCURSO DE ODIO EN LÍNEA CONTRA REFUGIADOS: ENTEXTUALIZACIÓN, INDEXICALIDAD E INTELIGIBILIDAD}

THE CIRCULATION OF ONLINE HATE SPEECH AGAINST REFUGEES: ENTEXTUALIZATION, INDEXICALITY AND INTELLIGIBILITY

Danillo da Conceição Pereira Silva* Instituto Federal de Alagoas Universidade Federal de Sergipe

RESUMO: Este artigo discute a circulação de discursos de ódio contra migrantes e refugiados venezuelanos no Facebook, bem como seus efeitos relativos à violência linguística, na construção de políticas discursivas de inteligibilidade do humano. Conceitualmente são articuladas perspectivas que tomam a linguagem enquanto performance, ou seja, como modo de ação social e política implicada na elaboração da realidade, com aquelas relativas à mobilidade do discurso e ao caráter indexical dos signos linguísticos. Em termos analíticos, focalizo os processos de entextulização, a indexicalidade e as ordens de indexicalidade mobilizadas nos atos de fala analisados, a fim de visibilizar o modo como Discursos historicamente construídos, que circulam translocal e transtemporalmente, comparecem em interações linguísticas situadas com vistas a reiterar semioticamente processos de hierarquização social. As interpretações construídas apontam para a entextualização de discursos xenofóbicos calcados na desumanização, na criminalização da migração e na patologização da diferença como instrumentos de produção de um Outro racializado e inferiorizado. PALAVRAS-CHAVE: Discurso de ódio. Circulação do discurso. Migrantes. Refugiados.

* Professor de Língua Portuguesa do Instituto Federal de Alagoas (IFAL). Doutorando e Mestre em Letras, com ênfase em Linguística Aplicada, pelo Programa de Pós-Graduação em Letras da Universidade Federal de Sergipe (PPGL/UFS). E-mail:danillo.silva@ifal.edu.br. 
RESÚMEN: Este artículo discute la circulación de discursos de odio contra migrantes y refugiados venezolanos en el Facebook, así como sus efectos relacionados a la violencia lingüística, en la construcción de políticas discursivas de inteligibilidad de lo humano. Conceptualmente se articulan perspectivas que comprenden el lenguaje como performance, o sea, como modo de acción social y política involucrado en la elaboración de la realidad, como aquellas relacionadas a la movilidad del discurso y al carácter indexical de los signos lingüísticos. En términos analíticos, me centro en los procesos de entextualización, la indexicalidad y los órdenes de indexicalidad movilizados en los actos de habla analizados, con el fin de visibilizar el modo como los Discursos históricamente construidos, que circulan translocal y transtemporalmente, aparecen en interacciones lingüísticas situadas para reiterar semióticamente procesos de jerarquización social. Las interpretaciones construidas apuntan a la entextualización de discursos xenófobos basados en la deshumanización, en la criminalización de la migración y en la patologización de la diferencia como como instrumentos de producción de un Otro racializado e inferior.

PALAVRAS CLAVE: Discurso de odio. Circulación del discurso. Migrantes. Refugiados.

ABSTRACT: This article discusses the circulation of hate speeches against Venezuelan migrants and refugees on Facebook, as well as their effects on linguistic violence, in the construction of discursive policies of human intelligibility. Conceptually, it articulates perspectives that take language as a performance, that is, as a mode of social and political action involved in the elaboration of reality, with those related to the mobility of discourse and the indexical character of linguistic signs. In analytical terms, one focuses on the processes of entextualization, indexicality and the orders of indexicality mobilized in the speech acts analyzed, in order to visualize the way in which historically constructed Discourses - which circulate translocal and trans-temporally - appear in situated linguistic interactions in order to reiterate semiotically, processes of social hierarchy. The constructed interpretations point to the entextualization of xenophobic discourses based on dehumanization, on the criminalization of migration and on the pathologization of difference as instruments of production of a racialized and inferiorized Other.

KEYWORDS: Hate speech. Circulation of the speech. Migrants. Refugees.

\section{INTRODUÇÃO}

Segundo dados do Alto Comissariado das Nações Unidas para Refugiados (ACNUR), o ano de 2018 foi, para o Brasil, aquele com maior índice de solicitações de refúgio. Certamente, o fluxo de pessoas venezuelanas em deslocamento para o Brasil, haja vista a grave crise humanitária interna que o país estava enfrentado, fez com que tal número aumentasse de forma expressiva. Do total de mais de oitenta mil pedidos registrados no ano passado, 61.681 deles foram realizados por venezuelanos (ACNUR, 2019). Apesar de esses serem os dados oficiais sobre os pedidos do estatuto formal de refugiado, com vistas ao acesso a um regime de proteção internacional específico, certamente, na multidão de outros migrantes venezuelanos cujos pedidos de refúgio ainda não foram julgados pelas instâncias competentes, há pessoas em situação de extrema violação de direitos humanos e cujo retorno ao país de origem significa risco iminente de morte ${ }^{1}$.

No bojo das complexas questões jurídicas, políticas, sociais e culturais produzidas pelas trajetórias de deslocamento desses corpos, um desafio encontrado pelos organismos internacionais, e por entidades civis engajadas na preservação de condições dignas de vida para pessoas migrantes e refugiadas, está na crescente onda de discursos de ódio a elas direcionados. Dada a gravidade dos efeitos desses discursos, cada vez mais frequentes nas mídias digitais e na esfera política graças à guinada de proporções mundiais ao nacionalismo e às políticas xenófobas de extrema direita, estratégias de enfrentamento têm sido pensadas em diferentes partes do mundo ${ }^{2}$.

\footnotetext{
1 "Refugiados são especificamente definidos e protegidos no direito internacional [...] como pessoas que estão fora de seus países de origem por fundados temores de perseguição, conflito, violência ou outras circunstâncias que perturbam seriamente a ordem pública e que, como resultado, necessitam de 'proteção internacional'. As situações enfrentadas são frequentemente tão perigosas e intoleráveis que estas pessoas decidem cruzar as fronteiras nacionais para buscar segurança em outros países, sendo internacionalmente reconhecidos como 'refugiados' e passando a ter acesso à assistência dos países, do ACNUR e de outras organizações relevantes [...]. A prática adotada pelo ACNUR é se referir a grupos de pessoas viajando em movimentos mistos como 'refugiados e migrantes”” (ONU, 2016).

${ }^{2}$ Uma amostra disso é a instalação de eventos e campanhas sobre o tema, como aquela realizada em 2017, em Bruxelas, por iniciativa da Aliança das Civilizações e da União Europeia, com apoio da Organização das Nações Unidas. Trata-se de um seminário sobre discurso de ódio contra refugiados e seus efeitos nocivos para políticas interculturais de integração e proteção, bem como a campanha voltada para espaços públicos virtuais: "Não espalhe o ódio", sob a hashtag \#SpreadNoHate.
} 
No campo dos estudos da linguagem, tem sido crescente o interesse pela compreensão do funcionamento e da circulação de atos de fala violentos, especialmente aqueles orientados contra grupos historicamente subalternizados, em espaços interacionais criados pelos recursos digitais de interconexão. Na esteira dessa preocupação, o presente trabalho tem como objetivo produzir uma compreensão situada acerca de esquemas de inteligibilidade e de políticas de reconhecimento do que conta como vida humana no contexto de tais discursos. Para tanto, é oferecido um entendimento da circulação de discursos de ódio contra migrantes e refugiados venezuelanos, em atos de fala engajados em comentários postados na fanpage do maior portal de notícias brasileiro, o G1, no Facebook. De modo geral, serão analisados comentários disparados em resposta à narrativa noticiosa intitulada "Após ataque de brasileiros 1,2 mil venezuelanos deixaram o Brasil, diz exército", publicada em 16 de agosto de 2018, a qual relata o retorno de migrantes e refugiados venezuelanos ao seu país de origem em função de um ataque xenofóbico ocorrido em Pacaraima, Roraima. $\mathrm{Na}$ ocasião, brasileiros expulsaram venezuelanos sob apedrejamento, incineração de seus pertences e destruição de seus abrigos.

Este artigo está organizado em três seções temáticas, afora introdução e conclusão. Na primeira delas, apresentarei uma concepção performativa sobre a linguagem e sobre os discursos de ódio, a qual sublinha os caminhos pelos quais enunciados se constituem enquanto formas de ação linguística, social e política. Na seção seguinte, em face à discussão sobre a mobilidade linguística, argumentarei acerca do fato de que para realizar violência, as práticas discursivas estabilizam sentidos em trajetória, mediante ordens específicas. Por fim, na terceira seção, mediante a explicitação dos procedimentos metodológicos empreendidos na geração de dados, discutirei o modo como os trânsitos textuais em funcionamento nos comentários analisados respondem a ordens de indexicalidade que apontam para Discursos nos quais as vidas de refugiados e migrantes são tomadas sob o signo da desumanização, da criminalização da migração e da patologização da diferença.

\section{DISCURSOS DE ÓDIO: LINGUAGEM, PERFORMATIVIDADE E VIOLÊNCIA LINGUÍSTICA}

Considerar os efeitos que determinados discursos podem produzir sobre pessoas ou grupos sociais implica, irredutivelmente, produzir um tipo de epistemologia sobre a linguagem que dê conta, por um lado, de uma posição acerca de sua natureza e, por outro, do tipo de relação que ela, a linguagem, estabelece com a realidade, especialmente com aquilo que de forma corrente se nomeia sob o rótulo de "realidade extralinguística". Nesses termos, questões importantes e ainda subjacentes aos estudos da linguagem se estabelecem: seria a linguagem um tipo de atividade cuja função está circunscrita ao expediente designativo e, por isso, considerável em termos do grau de fidelidade de sua representação ou mediação da realidade? Ou seria a linguagem uma forma de ação que produz e nomeia a realidade, na medida em que atos de linguagem empregados em contexto atendem a exigências rituais próprias das situações socioculturais a que se integram?

É recorrendo a um dilema retórico semelhante ao que aparece nas perguntas acima que o trabalho intelectual de John L. Austin, parcialmente sistematizado na compilação das conferências ministradas na Universidade de Harvard na década de 1950 e $60^{3}$, rompe com a tradição da filosofia analítica praticada no Ocidente e com seu modo de encarar a linguagem. Tal modo hegemônico tomava a linguagem enquanto modo de designação de uma realidade sempre exterior e cujo estudo se dava em função da análise lógica de enunciados artificiais, segundo suas condições de verdade, ou seja, segundo seu grau de fidelidade em relação às realidades extralinguísticas por eles descritas.

Ao contrário dessa perspectiva representacionalista e essencialista, o que Austin faz ao propor o abandono da distinção ente atos de fala constativos (aqueles que descreveriam a realidade) e atos de fala performativos (aqueles que agiriam na produção da realidade), passando a afirmar que todo enunciado é performativo, é alçar a performatividade ao estatuto comum da própria linguagem ordinária, sustentando, desse modo, que todo uso da linguagem se constitui uma forma de ação. Essa é uma guinada de visão que coloca linguagem, sujeito e sociedade numa relação de implicação inextricável ${ }^{4}$.

\footnotetext{
${ }^{3}$ Tal compilação foi publicada originalmente em inglês como How to do things with words (1962), com tradução feita para o português intitulada Quando dizeré fazer (1990).
}

${ }^{4}$ Recontextualizando as consequências epistemológicas e ontológicas subjacentes à ruptura realizada pelo pensamento austiniano sobre a linguagem no quadro das perspectivas da linguística, vejo que, conforme aponta Pennycook (2007, p. 38, tradução minha), "[...] a aceitação de tais questões dentro do domínio da linguística 
Na esteira do trabalho crítico elaborado por diferentes intelectuais como desdobramento dessa perspectiva austiniana sobre os atos de fala, a proposta desenvolvida por Jacques Derrida no Signature, evenent, context (1991) tanto reconhece sua potencialidade quanto submete-a a um exercício de desconstrução, o qual focaliza dois pontos principais: os resquícios de uma noção de "referência" subjacente à noção de "presença" e a necessidade de determinação total e precisa do contexto de produção de um ato de fala (situação total de fala) a fim de determinar sua força de ação e os efeitos do ato. Na leitura derridiana, é instaurada uma ruptura tanto com qualquer ideia de que um ato de fala só é capaz de realizar aquilo que enuncia em função da referência ou presença daquele que o profere, quanto com a obrigatoriedade da recuperação de um contexto original no qual os atos de fala foram enunciados para compreender aquilo que eles fazem. É em face desse modo de ler Austin que o filósofo franco-argelino desenvolverá as ideias de citacionalidade e iterabilidade ${ }^{5}$.

Apoiadas nessas perspectivas, as considerações de Judith Butler em Excitable speech: a politics of the performative (1997) acerca do discurso de ódio e dos efeitos da injúria linguística, no sentido dos efeitos políticos dos atos de fala performativos, leva a termo a proposta externalista de compreensão da linguagem, marcante no pensamento austiniano, bem como as críticas feitas a ele na leitura derridiana. Assim, Butler (1997) direciona sua argumentação no sentido de sustentar que o contexto não pode ser tomado como um momento concluso, hermético ou mesmo completamente determinável, bem como se oporá à tendência imanentista de julgar que determinadas palavras podem ter um sentido injurioso em si mesmas ou que este possa ser intensificado ou mitigado em função do contexto de ocorrência.

Nesse sentido, a perspectiva crítica proposta por Butler (1997) para a compreensão do discurso de ódio encontra seus termos numa definição de contexto de produção ritual dos atos de fala que ultrapassa limitações temporais ou espaciais, tornando-se "uma historicidade condensada", segundo a qual o contexto "[...] excede a si mesmo em direções passadas e futuras, um efeito de invocações anteriores e futuras que constituem a instância de proferimento e que escapam dela” (BUTLER, 1997, p. 3). Assim, o discurso de ódio se realiza, em alguma medida, em função da emergência/atualização de um contexto ritual de violência e injúria no qual aquele que é injuriado é interpelado a ocupar ${ }^{6}$ um lugar que torna precária ${ }^{7}$ sua condição, sua vida, quase sempre obliterando sua condição de humanidade (SILVA, 2019b). A este último ponto retornarei na seção seguinte.

Assim, a força que torna um enunciado capaz de produzir a violência linguística como efeito do que faz o discurso de ódio é instaurada em razão da inovação e, ao mesmo tempo, da dissimulação produzida pela "[...] sedimentação de seus usos na medida em que eles se tornaram parte do próprio nome, uma sedimentação, uma repetição que solidifica, que dá ao nome sua força” (BUTLER, 1997, p. 36). Desse ponto de vista, quando um sujeito profere um ato de fala violento,

[...] fala convencionalmente, ou seja, fala numa voz que nunca é completamente singular. Esse sujeito invoca a fórmula (o que não é a mesma coisa que seguir a uma regra), e isso pode ser feito com nenhuma ou pouca reflexão sobre o caráter convencional do que está sendo dito. A dimensão ritual da convenção implica em que o

sempre foi prejudicada pela obsessão linguística com a interioridade da linguagem, para muitos outros [na filosofia, na antropologia e afins] a questão de como fazemos as coisas com as palavras (e como as palavras fazem as coisas para nós) permaneceu uma perseguição-chave".

${ }^{5}$ Conforme a "estrutura grafemática geral" da comunicação, proposta por Derrida (1991), aplicável inclusive à comunicação performativa, todo signo, independentemente de sua modalidade de realização, é passível de ser extraído de seu contexto de origem e de ser inserido, enxertado em outros novos contextos, ou seja, na ausência do contexto "original" e à revelia das “intenções” de seu “uso primeiro", numa dinâmica insaturável de produção de significados a partir da relação entre repetição/alteração, identidade/diferença, citação/iteração.

${ }^{6}$ Apesar de reconhecermos a interpelação como parte importante do processo de produção da injúria, aquele a quem o ato de fala violento é direcionado (adress) pode agir no sentido de rejeitar essa dinâmica de posicionamento que o conduz a habitar um lugar de vulnerabilidade e violação desde a linguagem. Desse modo, a noção austiniana de uptake, enquanto condição fundamental para o sucesso do performativo relativizar a implicação entre interlocutores na realização de uma ação conjunta, ganha particular relevância. É dessa possibilidade de malogro na repetição ritual que emergem espaços para, em termos discursivos, apropriações linguísticas de resistência e inflexões políticas decorrentes, a exemplo do que ocorre com o termo queer no universo anglófono, segundo discorre Butler (1997), ou da ocupação de termos como "vadia", no contexto brasileiro do movimento político feminista da "Marcha das Vadias".

${ }^{7}$ Neste artigo, como demonstrarei em outros momentos, “precário” faz alusão à posição teórica desenvolvida por Judith Butler em Vida precária: os poderes do luto e da violência (2019), publicado originalmente em 2004, e em Quadros de guerra: quando a vida épassível de luto? (2015), publicado originalmente em 2009. Em linhas gerais, a precariedade butleriana diz respeito, por um lado, a uma condição geral de suscetibilidade à violência gratuita, a qual todas as formas de vida estão expostas desde sua dimensão corporal; e, por outro, ao fato de que essa condição de precariedade é desigualmente distribuída entre os sujeitos, levando-se em conta sua ininteligibilidade em face de marcos normativos (sociopolíticos) específicos - a exemplo de raça, gênero, sexualidade, classe, nacionalidade. 
proferimento é constituído pelos momentos antecedentes e, de fato, futuros que são fechados pelo momento em si. Quem fala quando a convenção fala? Em que momento a convenção fala? Em certo sentido, ela é um conjunto de vozes herdado, um eco de outros que fala como um 'eu'. (BUTLER, 1997, p. 25)

Em função dessa perspectiva, conforme explorei em trabalhos anteriores (SILVA, 2019a, 2019b, 2019c), entendo que considerar a historicidade e as múltiplas vozes sociais que falam no discurso violento é também, em certo sentido, levar em conta as dinâmicas de temporalidade e espacialidade constitutivas de sua produção e circulação translocal (BLOMMAERT, 2010), desde a cena discursiva específica em que a injúria é praticada até as instâncias mais remotas que nela se atualizam, mediante processos contínuos de criação e de pressuposição de contextos (FABRÍCIO, 2014) injuriosos.

Assim, nas políticas de produção desse "outro" (BHABHA, 1998) que é violentado no/pelo discurso de ódio, estão em jogo as forças de subordinação próprias das espacialidades e temporalidades em que ele se realiza e dos regimes discursivos e metadiscursivos nelas implicadas. Nesse sentido, tomando como referência a configuração social e histórica do Brasil, tais processos se dão especialmente em face de uma matriz de poder e dos regimes de hierarquização da vida constitutivos e vigentes desse/nesse território específico. Ou seja, a violência linguística funciona pela reiteração de violências pautadas em aspectos como raça, classe, gênero, sexualidade, nacionalidade, idade, diversidade funcional, entre outros marcadores sociais da diferença, implicados na dinâmica corpóreodiscursiva do sistema-mundo colonial/moderno capitalista (GROSFOGUEL, 2008).

Uma vez delineada a perspectiva aqui assumida para a compreensão dos discursos de ódio e da violência linguística por eles produzida, explorarei, na seção seguinte, a possibilidade de interpretação crítica desses fenômenos segundo a perspectiva pragmática e semiótica da mobilidade textual. De modo particular, validarei discussões sobre processos de entextualização, indexicalidade e ordens de indexicalidade, articulando-os, por fim, com os processos sociopolíticos que constituem marcos de inteligibilidade em jogo na constituição da violência.

\section{CIRCULAÇÃO DE DISCURSOS, TRÂNSITOS TEXTUAIS E POLÍTICAS DE INTELIGIBILIDADE}

Do ponto de vista sobre o discurso de ódio aqui tomado, é válido pensar que, para produzir seus efeitos violentos, "a violência na linguagem requer movimento", ou seja, atos de fala engajados na produção da violência linguística funcionam "movendo-se pelos espaços sociais" (SILVA, 2017, p. 12), a fim de serem reconhecidos como uma conexão que os vincula a usos violentos anteriores. Assim, tais atos de fala se constituem mediante o exercício contínuo de "repetir os rituais e, ao mesmo tempo, interrompê-los", extraindo a força que os torna capazes de realizar aquilo que enunciam, no fluxo desse movimento (con)textual, da história de usos anteriores incorporados num uso atual, dissimulando completamente a premência desse "processo de extração" (SILVA, 2017, p. 12) de sentidos.

Assim, com vistas à produção de uma interpretação sobre os modos de circulação de discurso de ódio, especificamente endereçado contra pessoas em situação de refúgio ou migração forçada, objetivo deste artigo, parece-me bastante produtiva a perspectiva da mobilidade de textos e discursos enquanto signos indexicais, ou seja, que apontam para sua própria trajetória de deslocamento e para adensamentos socioculturais mais estáveis (FABRÍCIO, 2014). Nesse sentido, tomo como construtos teórico-analíticos importantes para a compreensão do discurso de ódio e da violência na linguagem noções como entextualização, conforme proposta por Bauman e Briggs (2010); indexicalidade, de acordo com Silverstein (2003), e ordens de indexicalidade, como pensado por Blommaert $(2005,2010)$. Tais elementos serão fundamentais para a produção de entendimentos sobre os nexos macrocontextuaismicrocontextuais em jogo na produção de significações violentas e desumanizantes. 
Segundo os estudos linguísticos e socioantropológicos da performance, a entextualização é compreendida como a propriedade que garante ao Discurso ${ }^{8}$ a possibilidade de assumir a forma semiótica de um texto numa dada situação comunicativa e, assim, tornarse "[...] passível de extração, de transformar um trecho de produção linguística em uma unidade - um texto - que pode ser extraído de seu cenário interacional" (BAUMAN; BRIGGS, 2010, p. 206). Os textos assumem trajetos pluridirecionais de circulação, mediante dinâmicas constantes de entextualização-descontextualização-recontextualização. À medida que um texto cumpre sua trajetória, ou seja, à medida que ele viaja de uma prática discursiva a outra, produzindo novos contextos, tanto leva consigo traços de sentido de sua história de usos - história de circulação - quanto instaura novos sentidos, numa dinâmica insaturável de mobilidade e de produção de significados.

Em outras palavras, podemos dizer que contextos são performados, ou seja, produzidos, e se estabelecem num estado de fluxo, no qual integram, ainda que de forma não pacífica, estabilidade e renovação, sentidos estabelecidos e aqueles emergentes. Assim, "[...] a ênfase na motilidade incessante de espaço-temporalidades é fundamental para a compreensão dos significados em trânsito na contemporaneidade" (SZUNDY; FABRÍCIO, 2019, p. 74), uma vez que velocidade e fluidez são características marcantes dos processos comunicativos nos quais textos são descentrados de seus contextos originais e recentrados em novos contextos, especialmente mediante as características próprias das mídias digitais conectadas à web, ambiência na qual se desenrolam as práticas discursivas aqui analisadas.

Em razão dessa concepção que encara os textos como citáveis e iteráveis, graças à sua dinâmica constante de entextualização, podese inferir que os signos empregados em contexto apontam para significados que ultrapassam o momento específico de seu emprego, ao que podemos chamar de indexicalidade (SILVERSTEIN, 2003). Dessa forma, quando mobilizados numa interação específica, recursos semióticos são capazes de indexar (apontar para) repertórios de sentido socioculturais mais densos, estabelecendo uma relação imbricada entre os sentidos localmente produzidos (discursos) e instâncias translocais de significação (Discursos). Desse modo, são estabelecidos, assim, elos significativos entre diferentes instâncias de significação e espaço-temporalidades. Nesse sentido, os usos linguísticos, além das ligações entre formas semióticas e contextos (dimensão pragmática), funcionam mediante sua dimensão metapragmática (SILVERSTEIN, 2003), ou seja, aquela cuja natureza histórica e social da linguagem regem as práticas semióticas, as quais “[...] são conectadas a vários sistemas hierárquicos, na medida em que indiciam diferenças e desigualdades e orientam as ligações entre textos, cotextos e contextos" (PINTO; AMARAL, 2016).

Conforme propõe Blommaert (2010) na sua leitura da indexicalidade, esta funciona segundo dois regimes distintos. De um lado, a ordem indexical, a qual se refere à possibilidade de os signos indexicalizarem os Discursos das grandes narrativas que orientam a vida social e, de outro, a ordem de indexicalidade, baseada na concepção foucaultiana de ordem do discurso, segundo a qual a produção discursiva é socialmente controlada em função de normas, valores e hierarquias, aos quais fazem referência os processos de indexicalização de Discursos. É a esse segundo construto, a ordem de indexicalidade, que recorrerei a fim de compreender quais regimes de verdade e esquemas normativos estão em funcionamento nos processos de entextualização em curso no discurso de ódio contra pessoas imigrantes e refugiadas.

Buscando o desenvolvimento de uma interpretação que articule a produção de sentidos nas práticas de linguagem analisadas com as ordens do discurso que as mobilizam, pretendo argumentar que as trajetórias de textos em funcionamento na circulação do discurso de ódio estão diretamente implicadas em processos sociopolíticos mais amplos, a exemplo daqueles em jogo na produção de esquemas de inteligibilidade e de políticas de reconhecimento (BUTLER, 2017) do que conta como vida humana. Em certo sentido, são esses mecanismos políticos e subjetivos de gestão de um estatuto de vida humana válida, desigual e hierarquicamente distribuído, o qual é discursivamente produzido, que estão no bojo da violência linguística praticada contra pessoas em situação de refúgio e migrantes forçados.

\footnotetext{
${ }^{8}$ Para fins de maior definição, mobilizo, neste artigo, a proposta de Gee (2004) ao se referir ao discurso como a produção de linguagem em uso e ao Discurso como construtos sócio-históricos e ideológicos mais densos, os quais se instauram mediante regimes de verdade e ordens que regulam a produção e a circulação do dizer, em sentido foucaultiano.
} 
Para tanto, a pergunta de Butler (2017) parece uma intrigante provocação para se considerar aquilo que está em jogo na circulação de atos de fala violentos: "o que seria necessário para apreender o caráter precário das vidas perdidas na guerras [e em outras formas de violência gratuita], mas também fazer com que essa apreensão coincida com uma opção ética e política às perdas que a guerra acarreta?”. É em função dessa pergunta, a qual põe em suspeição o alegado estatuto de vida válida do qual gozariam todas as vidas humanas, segundo um imaginário universalista, que Butler (21070 vai construir seu argumento em três direções: $a$ ) nem todas as vidas são social e politicamente reconhecidas como tal; $b$ ) a distribuição desse reconhecimento é feita de forma desigual e contextual, de modo que uma hierarquia de vidas é estabelecida; e c) em função dessa impossibilidade que determinadas vidas têm de serem lidas como vidas válidas, há uma desigual distribuição do que ela chama de precariedade, ou seja, da condição de ser passível de violência injusta e gratuita.

Nesse sentido, meu argumento é de que o caráter performativo da linguagem engajada na violência linguística age em função do modo como os sujeitos em interação negociam a força injuriosa da herança de uso de discursos violentos, os quais, por sua vez, instauram políticas de reconhecimento específicas, gerindo discursivamente as fronteiras desse reconhecimento, mediante políticas de entextualização e de indexicalidades e suas ordens, como explorarei na seção seguinte. Ou seja, no fato de que "[...] determinadas vidas são percebidas como vidas, ao passo que outras, embora aparentemente estejam vivas, não conseguem atingir uma forma percebível como tal" (BUTLER, 2017, p. 28), há uma instanciação da linguagem na qual esses processos discursivos operam de forma insistente.

\section{ENTEXTUALIZAÇÃO, INDEXICALIDADE E ORDENS DE INDEXICALIDADE: A PRODUÇÃO SEMIÓTICA DE VIDAS (IN)INTELIGÍVEIS}

A fim de amparar as discussões que tenho articulado ao longo deste artigo, analiso, nesta seção, a circulação do discurso de ódio em interações online ocorridas na página do site de notícias G1, na rede social Facebook, especificamente relacionadas à notícia "Após ataque de brasileiros 1,2 mil venezuelanos deixaram o Brasil, diz exército", de autoria de Jackson Félix e Emily Costa, divulgada em 19 de agosto de 2018. Tal postagem, replicada na referida rede social a partir do site do G1 Roraima, produz uma narrativa noticiosa acerca do retorno de migrantes forçados venezuelanos ${ }^{9}$ ao seu país de origem, em função do episódio de violência xenofóbica, nacionalmente repercutido, em que grupos de brasileiros apedrejaram e expulsaram venezuelanos na fronteira entre Brasil e Venezuela, na cidade de Pacaraima, Roraima. No episódio, os migrantes tiveram seus pertences queimados e foram destruídos os alojamentos improvisados em que vivam com suas famílias, sob gritos e palavras de ordem como "Taca fogo! Taca fogo! Queima tudo! Queima tudo! Fora! Fora!" e ao som do hino nacional brasileiro cantado pelos agressores ${ }^{10}$. Segundo relata a notícia, a agressão teria sido motivada por uma denúncia à Polícia Militar feita pela família de um comerciante que teria sido assaltado, supostamente por venezuelanos.

\footnotetext{
${ }^{9}$ Optei por me referir às pessoas venezuelanas utilizando essas duas referências, haja vista a especificidade jurídica do status de refugiado, em relação à legislação vigente, e a impossibilidade de determinação, da minha parte, de qual a condição real de cada uma das pessoas envolvidas nesse evento.

${ }^{10}$ Áudio transcrito de um vídeo amador gravado em Pacaraima (RO) durante o referido ataque xenofóbico a venezuelanos e postado na rede social Youtube.
} 
G1 - O Portal de Noticias da Globo

19 de agosto de $2018 \cdot 3$

No sábado, imigrantes tiveram acampamentos queimados e foram expulsos de Pacaraima (RR), na fronteira com o país vizinho, após assalto e agressão a comerciante. Cidade amanheceu com ruas vazias https://glo.bo/2PnqLxq \#G1

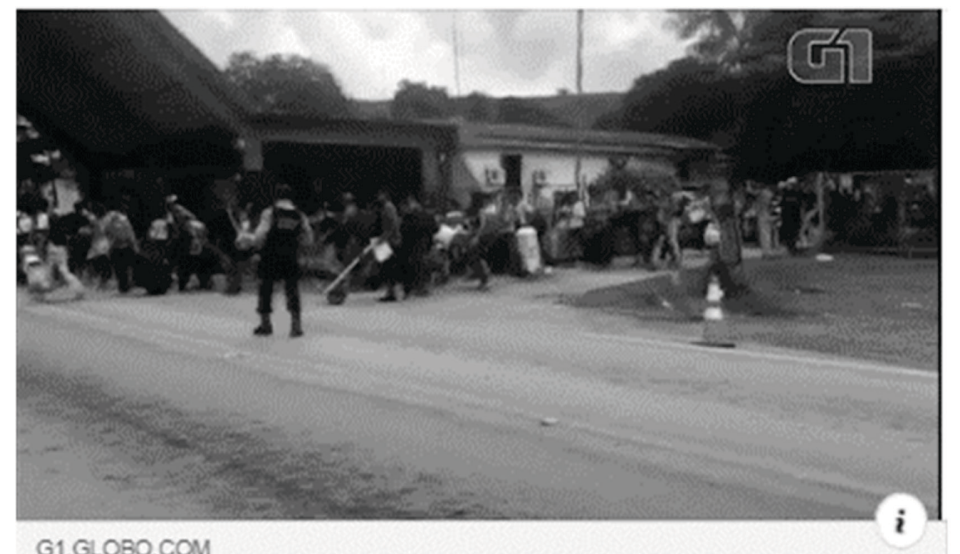

G1.GLOBO.CON

Após ataques de brasileiros, 1,2 mil venezuelanos deixaram o Brasil, diz Exército

(1) 2 mil comentários 10 mil mil compartilhamentos

Figura 1: Matéria do G1 sobre ataque de brasileiros a venezuelanos

Fonte: G1, 2019

Conforme ilustra a Figura 1, a notícia produziu um engajamento considerável desde sua postagem, contando, até a data do seu acesso para esta pesquisa, com dez mil reações, dois mil comentários e 1,1 mil compartilhamentos. Do ponto de vista metodológico, esta pesquisa pode ser identificada como qualitativa e de cunho interpretativista (DENZIN; LINCOLN, 2006), ou seja, pautada no pressuposto de que singularidades da vida social, como os comentários em rede social, possuem relevância de investigação, tanto porque nesse tipo de pesquisa não se busca a observação de padrões universalizantes ou indiscriminadamente replicáveis, com também pela possibilidade de que situações particulares possam oferecer nuances para a compreensão de processos socioculturais mais amplos. Nesse tipo de pesquisa, especialmente quando praticada a partir da produção de dados de comunicação em meios digitais, "[... a amostragem do material é intencional e a análise do material coletado é bastante flexível” (FLIKE, 2008, p. 249). Assim, para fins de identificação da postagem e de seleção dos comentários no Facebook, foram utilizados os recursos de busca e filtragem próprios dessa rede social, por meio da escolha do perfil de busca, a partir dos critérios oferecidos pelo site, quais sejam: ano de postagem (2018), fonte (G1 - O portal de notícias da Globo) e palavras de busca (REFUGIADOS + VENEZUELANOS + EXPULSOS). 


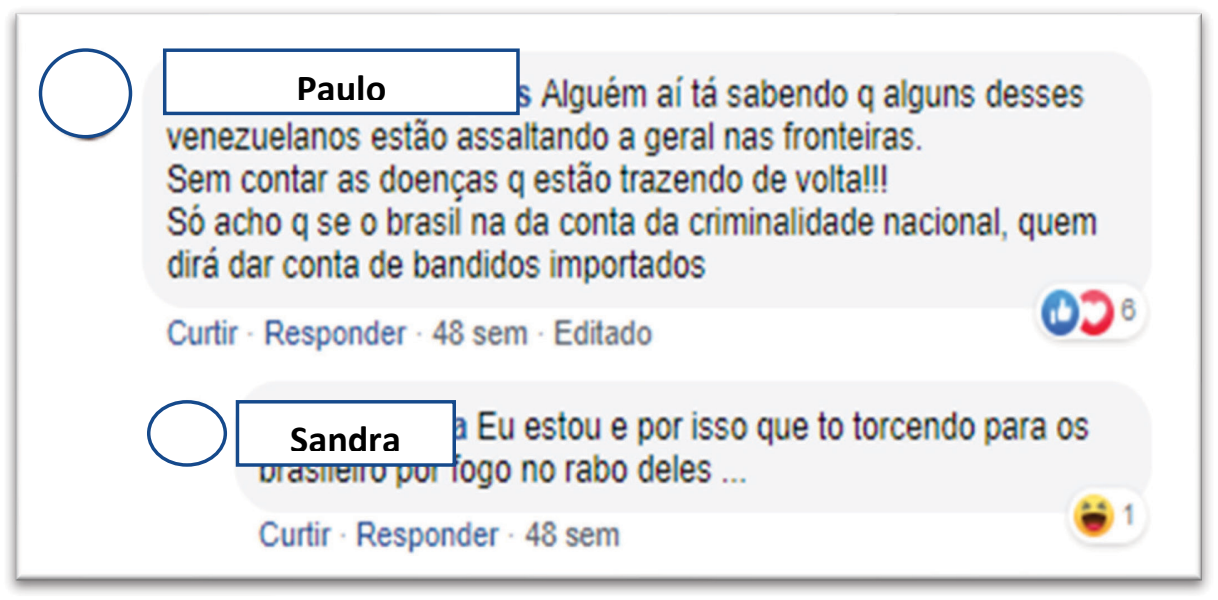

Figura 2: Interação online entre Paulo e Sandra na página do G1 no Facebook.

Fonte: G1, 2019

No comentário produzido por Paulo ${ }^{11}$, na Figura 2, os recursos linguísticos mobilizados indexicalizam Discursos que significam sócio-historicamente pessoas refugiadas, ou em situação de deslocamento forçado, como transgressoras, criminosas, ameaçadoras, atribuindo a elas, de modo generalizado (assaltando geral nas fronteiras), à revelia da tentativa de limitar o escopo da afirmação por meio de uma expressão partitiva (alguns desses venezuelanos) com efeito modalizador, um comportamento que poria em risco a segurança física e patrimonial dos nacionais, os brasileiros. Apesar de não haver uso de sinal interrogativo, a configuração frasal parece sugerir que se tratava de uma sentença interrogativa (Alguém aí tá sabendo q alguns desses venezuelanos estão assaltando a geral nas fronteiras?), o que é redefinido, ao final do comentário, pelo emprego do item linguístico que se refere às pessoas venezuelanas em situação de refúgio, de forma irônica, como bandidos importados.

Nesse contexto, a questão humanitária posta pela situação de violação de Direitos Humanos e de exposição a diferentes formas de violência em que se encontra o grupo populacional tematizado na matéria, expulso de forma também violenta numa reação xenofóbica de brasileiros, é entextualizada no comentário de Paulo como um problema de criminalidade. E, para além disso, como uma situação que não diz respeito ao Brasil ou aos/às brasileiros/as, mas um problema importado, uma sobrecarga que excede a capacidade resolutiva do próprio país em face dos seus próprios problemas, entendidos em face de uma criminalidade nacional.

Assim, poderíamos dizer que, no discurso de ódio produzido no comentário de Paulo, os signos empregados nesse contexto indexam Discursos que mobilizam uma ordem de indexicalidade da criminalização de migrantes forçados/refugiados, segundo a qual tais pessoas são entendidas, de modo generalizado, como moralmente degeneradas e potencialmente perigosas. É sob o influxo desse processo de valoração e hierarquização das vidas, indexado no ato de fala violento proferido pelo comentador em questão, que as dimensões simbólicas da condição de precariedade são desigualmente distribuídas, significando, assim, os/as venezuelanos/as como suscetíveis a processos de violação gratuitos e indiscriminados, acentuando sua condição de vulnerabilidade desde o nível ontológico.

Ainda em função do modo como a entextualização acontece no comentário de Paulo, os sentidos localmente produzidos no texto que ele elabora se articulam com dinâmicas de produção do "Outro" como adoecido, segundo perspectivas que significam a diferença como patologizada. Por conseguinte, as pessoas venezuelanas são significadas, mediante um ordenamento de valores e normas que as tomam sob o signo da ameaça, dessa vez recontextualizada no âmbito da saúde, em face do entendimento da sua presença como ligada à exposição da vida (dos nacionais, lidos como saudáveis) ao risco, ao contágio com patologias supostamente já superadas no Brasil, por isso associadas à imagem de um passado incivilizado, sem condições urbanísticas de promoção da saúde,

\footnotetext{
${ }^{11}$ Assim como acontece nos demais comentários extraídos do Facebook, os nomes reais dos comentadores foram substituídos por nomes fictícios, embora tenham sido escolhidos nomes usualmente associados à identidade de gênero declarada pelos comentadores em seus perfis na rede social. Tal ação visa garantir o anonimato de suas identidades, ainda que todos os materiais utilizados nesta pesquisa estejam em domínio público na internet.
} 
sem higiene, sem assepsia e relativo ao atraso e ao primitivismo. Em função disso, podemos inferir o funcionamento de uma ordem de indexicalidade da patologização da diferença como instância reguladora da produção discursiva em torno dos refugiados no comentário violento produzido por Paulo.

De certa maneira, os esquemas de inteligibilidade oferecidos pela política de reconhecimento produzida na circulação do discurso de ódio, conforme visto até aqui, estão fundados na classificação e racialização das vidas (BUTLER, 2017) em dois grupos distintos e hierarquizados, seja em função do binarismo moral (ameaçados/vítimas versus ameaçadores/criminosos), seja em função do binarismo corporal (saudáveis/puros versus doentes/contaminados). Assim, aparece validada na classificação do que conta como vida humana a "[...] divisão entre duas categorias mundiais cada vez mais reificadas: de um lado, o mundo limpo, saudável e visível; do outro, o mundo dos 'remanescentes' residuais, sombrio, doente e invisível" (AGIER, 2008 apud BAUMAN, 2017, p. 88). Nesses termos, ao passo que as trajetórias corporais das pessoas refugiadas desestabilizam e/ou ameaçam esquemas de inteligibilidade nacionais, calcados em nacionalismos essencialistas e em projetos identitários hegemônicos, as trajetórias textuais mobilizadas em função/em reação dessas/a essas trajetórias corporais e seus efeitos funcionam como sintoma da implicação inescapável entre mobilidade corporal e mobilidade textual (PINTO; AMARAL, 2016).

Aprofundando essa dimensão dos efeitos produzidos nas reações violentas à mobilidade corporal vivenciada por pessoas refugiadas, o comentário de Sandra, o segundo exposto na Figura 2, em endosso e em resposta ao comentário de Paulo, entextualiza Discursos relativos ao caráter corpóreo da violência, tornando salientes os limites entre a violência linguística, aquela perpetrada no discurso, e aquela de caráter físico, conforme já discuti em outros momentos (SILVA, 2019b). Nesse sentido, a dimensão indexical dos signos linguísticos empregados pelo ato de fala violento proferido pela comentadora aponta para significados translocais relativos à ação de infligir castigo físico ou tortura a essas pessoas como forma de punição disciplinar, haja vista o modo como elas são significadas em consequência dos valores normativos mobilizados pelas ordens de indexicalidade da criminalização de migrantes forçados/refugiados e da patologização da diferença.

Pensando nos sentidos da geografia moral do corpo validada na sociedade brasileira, de cariz heteronormativo, a região sobre a qual a fala injuriosa de Sandra sugere que seja praticada a violência (por fogo no rabo deles) indexicaliza sentidos relativos à feminilização do outro como condição para a prática da violência sobre ele (SILVA, 2012). Nesse contexto, a relação estabelecida entre o emprego de recursos semióticos indexicais em encontros interacionais situados e a produção de corpos vulnerabilizados, violentados ou violentáveis, na circulação do discurso de ódio contra pessoas refugiadas, conforme discutem Pinto e Amaral (2016, p. 161), tomam "[...] os recursos linguísticos como parte da historicidade dos corpos, seu passado, presente e futuro colonial, nacional, racial, de gênero, integram, rearticulam e criam interligações com os sistemas de diferenciações dos corpos".

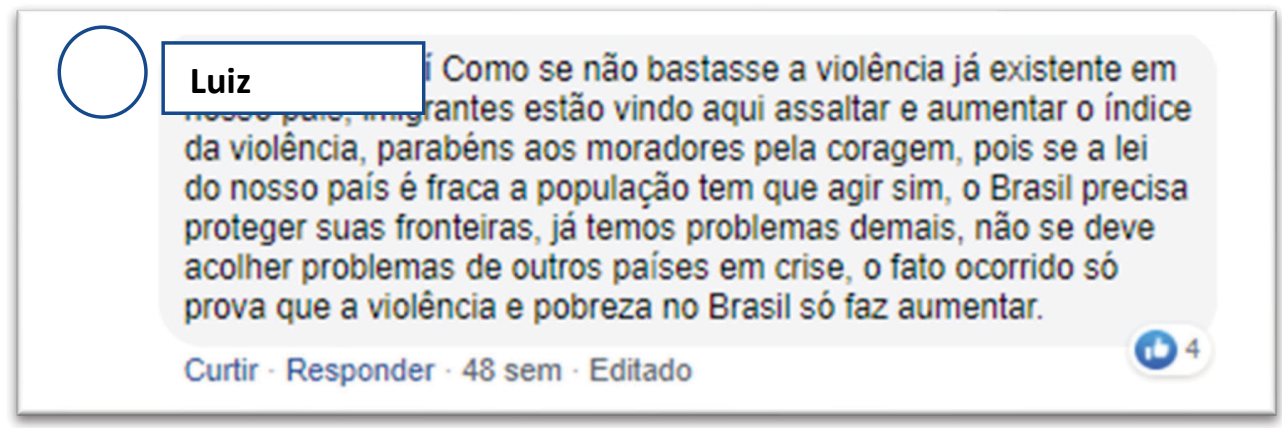

Figura 3: Comentário de Luiz à matéria do G1 no Facebook

Fonte: G1, 2019 
No comentário de Luiz, registrado na Figura 3, o processo de entextualização em curso faz precipitar Discursos que significam os/as refugiados/as venezuelanos/as como sujeitos perigosos e criminosos, a exemplo do que acontece também nos comentários analisados da Figura 2. Ou seja, a circulação dos discursos de ódio no comentário em análise cita/itera, repete e atualiza sentidos ligados aos valores e às normas em funcionamento na ordem de indexicalidade da criminalização de migrantes forçados/refugiados. Em função desse quadro de regulação do funcionamento da linguagem, fica saliente também, no curso desse ato de fala violento, a indexicalização de Discursos que promovem o apagamento do sentido da crise humanitária que atinge a Venezuela, a qual causa o deslocamento forçado de seus habitantes, agenciando, assim, a recusa por parte do comentador em oferecer reconhecimento a esses sujeitos em situação de violência, mediante o afastamento da "obrigação ética" (BUTLER, 2018) instaurada pela condição de precariedade e vulnerabilidade em que se encontram.

Signos como os imigrantes estão vindo aqui assaltar e aumentar o índice de violência apontam para esse apagamento ou para a recusa do reconhecimento das vidas venezuelanas como passíveis de luto (BUTLER, 2017) e, por isso, de reconhecimento enquanto vidas humanas, em função da inversão da relação vítima-violentador. As pessoas refugiadas, as quais deixaram seu país de origem sob o suplício de complexas e imbricadas situações de exposição à violência e que são, no curso dos fatos narrados pelo texto noticioso a que os comentários se referem, também vítimas de violência, expulsão e depredação, têm o reconhecimento de sua condição de sofrimento negada, sendo, então, significadas como aquelas que vieram ao Brasil com o objetivo de assaltar e aumentar o índice da violência, ou seja, de causar a violência contra os corpos nacionais.

Discursos de desumanização também são entextualizados em não se deve acolher problemas de outros países em crise, uma vez que o que está em jogo no processo de uma política de imigração e de acolhida de refugiados são as pessoas nessa condição, são corpos, e não propriamente problemas, nem mesmo aqueles potencialmente gerados pela gerência biopolítica do Estado em deixar sujeitos nessa condição entregues a diferentes tecnologias de controle e de exposição à lógica do fazer viver, deixar morrer (FOUCAULT, 1998). Longe de se tratar de um equívoco, tais sentidos indexicalizam esquemas de inteligibilidade a partir dos quais a vida e o corpo migrantes/refugiados configuram-se exatamente num problema, num impasse para as formas reiteradas/insistentes de enquadramento do que conta como uma vida.

É segundo tais perspectivas que podemos pensar na gestão da vida de pessoas em condição de refúgio como gestão do "refugo humano", daquilo "[...] sem função útil para desempenharem na terra em que chegaram e na qual permanecerão temporariamente, nem a intenção ou perspectiva realista de serem assimilados e anexados ao novo corpo social" (BAUMAN, 2004, p. 98). Nesse sentido, o que está em jogo na circulação do discurso de ódio contra essas pessoas são políticas de reconhecimento que se recusam a reconhecer "pessoas destituídas de qualidades", as quais “[...] foram depositadas num território sem denominação, enquanto todas as estradas que levam de volta a lugares significativos e a espaços em que significados socialmente legíveis podem e são forjados no cotidiano foram bloqueados para sempre" (BAUMAN, 2004, p. 98). Em função desses sentidos, posso argumentar, também, acerca da mobilização de uma ordem de indexicalidade de desumanização dos refugiados.

No comentário de Luiz, são ainda entextualizados Discursos de justiçamento, ou seja, aqueles relativos à validação de práticas de violências punitivas, tomadas como suplícios disciplinares, infligidas contra pessoas acusadas de práticas criminosas, sem a garantia do devido processo legal, do trânsito em julgado, das possibilidades do contraditório ou mesmo de ampla defesa, conforme preconizam as garantias básicas da narrativa jurídica dos direitos fundamentais ou dos direitos humanos. Em geral, casos de justiçamento ocorrem em face de pânico moral e/ou do ímpeto de vingança coletiva contra sujeitos considerados culpados por determinados delitos, especialmente aqueles que mobilizam por apelo popular. Tal prática, bastante comum na sociedade brasileira contemporânea, especialmente sob os argumentos da moralização enquanto ação corretiva do suposto criminoso ou da lentidão ou ineficácia do Estado em garantir o acesso efetivo à justiça por vias formalmente legais, não pode ser entendida fora das lógicas de distribuição da culpa e de acesso a direitos e à justiça próprios do sistema-mundo colonial/moderno capitalista (GROSFOGUEL, 2008).

Assim, ao parabenizar a ação de justiçamento realizada por brasileiros moradores de Pacaraima (RO) - expulsão dos/as refugiados/as mediante linchamento, destruição de abrigos e incineração de seus pertences -, como resposta a um suposto crime cometido por dois venezuelanos contra brasileiros (parabéns aos moradores pela coragem, pois se a lei do nosso país é fraca, a 
população tem que agir sim, o Brasil precisa proteger suas fronteiras), os signos linguísticos empregados pelo comentador na elaboração do seu ato de fala violento apontam para hierarquias subjetivas nas quais o reconhecimento dos venezuelanos como sujeitos de direitos humanos lhes é negado, justamente pela sua condição de ininteligibilidade como vida humana, por isso excluída da categoria política hegemônica de "sujeito de direitos".

Assim, as táticas do Discurso nos comentários que exercem a violência linguística contra tais sujeitos jogam no sentido de destituílos de sua condição reconhecível de humanidade (BUTLER, 2017), expondo-os/as a multidimensionais formas de violência e, por fim, ao processo de naturalização ritual de sua condição de vidas radicalmente sujeitas à morte. Aqui, segundo argumenta Foucault (1999, p. 306), "[...] por tirar a vida não entendo simplesmente o assassínio direto, mas também tudo o que pode ser assassínio indireto: o fato de expor à morte, de multiplicar para alguns o risco de morte ou, pura e simplesmente, a morte política, a expulsão, a rejeição, etc.”.

\section{PARA EFEITO DE CONCLUSÃO: O QUE CORPOS E TEXTOS EM MOVIMENTO DIZEM/FAZEM?}

Em função dos caminhos teórico-analíticos trilhados ao longo deste artigo, que nem de longe almeja configurar-se num arcabouço fechado sobre a multidimensional questão a que se dedica, acredito ter sido possível: por um lado, compreender o modo como a linguagem, graças a seu caráter performativo, está engajada na produção da violência contra pessoas migrantes e refugiadas nos comentários online analisados, e, por outro, oferecer problematizações acerca da circulação dessa modalidade de discurso de ódio, em face de lógicas que significam.

Ou seja, em razão do entendimento de processos citacionais/iterativos, de repetição/alteração de signos, em funcionamento na força da história de usos implicadas nos atos de fala analisados - mediante diferentes regimes de entextualização e indexicalização - foi possível discorrer acerca dos esquemas de inteligibilidade e das políticas de reconhecimento em ação no discurso de ódio dirigido a migrantes e refugiados. Assim, as vidas desses sujeitos são semioticamente constituídas como não vidas, como vidas ininteligíveis segundo enquadramentos específicos do que pode ser considerado como vida humana, em última instância, tomadas como vidas suscetíveis à morte, como vidas matáveis.

Desse modo, numa visada que articula a compreensão da mobilidade textual como indissociável da mobilidade corporal, acredito que, especialmente no que tange ao discurso de ódio, o escrutínio crítico desses atos de fala oferece-nos a possibilidade de desnaturalizar políticas de significação engajadas na produção performativa de vidas precárias, desigualmente sujeitas à violência indiscriminada. Isso especialmente quando corpos em trajetória desafiam as normas de reconhecimento do humano, segundo um ideal normativo específico (nacionalidade, por exemplo) e, assim, acabam sujeitos a trajetórias de textos que realizam violências linguísticas diretamente articuladas a outras formas de violência, praticadas no sentido de reestabelecer esquemas de reconhecimento hegemônicos implicados na hierarquização de vidas e de corpos.

\section{REFERENCIAS}

ACNUR. Dados sobre refúgio no Brasil. 2018. Disponível em: https://www.acnur.org/portugues/dados-sobre-refugio/dados-sobrerefugio-no-brasil/. Acesso em: 24 jul. 2019.

AUSTIN, J. L. How to do thhings with words. Cambridge: Harvard University Press, 1962.

AUSTIN, J. L. Quando dizeré fazer. Trad. Danilo Marcondes de Souza Filho. Porto Alegre: Artes Médicas, 1990. 
BAUMAN, R.; BRIGGS, C. Poética e performance como perspectivas críticas sobre a linguagem e a vida social. Ilha Rev. Antropologia, Florianópolis, v. 8, n. 1,2, p. 185-229, 2006.

BAUMAN, Z. Vidas Desperdiçadas. Rio de Janeiro: Zahar, 2004.

BAUMAN, Z. Estranhos à nossa porta. Rio de Janeiro: Zahar, 2017.

BHABHA, H. O local da cultura. Belo Horizonte: EDUFMG, 1998.

BLOMMAERT, J. Discourse. A critical introduction. Cambridge: Cambridge University Press, 2005.

BLOMMAERT, J. The sociolinguistics of globalization. Cambridge: Cambridge University Press, 2010.

BUTLER, J. Excitable speech: a politics of the performative. London: Routledge, 1997.

BUTLER, J. Quadros de guerra: quando a vida é passível de luto. Rio de Janeiro: Civilização Brasileira, 2017.

BUTLER, J. Corpos em aliança e a política das ruas: notas para uma performatividade da assembleia. Rio de Janeiro: Civilização Brasileira, 2018.

DENZIN, N. K; LINCOLN, Y. S. O planejamento da pesquisa qualitativa: teorias e abordagens. Tradução Sandra Regina Netz. Porto Alegre: Artmed, 2006.

DERRIDA, J. Limited Inc. Trad. Constança Marcondes Cesar. Campinas: Papirus, 1991.

FABRÍCIO, B. F. Transcontextos educacionais: gêneros, sexualidades e trajetórias de socialização na escola. In: SILVA, D.; ALENCAR, C. N.; FERREIRA, D. M. M. (org). Nova Pragmática: modos de fazer. São Paulo: Cortez. 2014. p. 145-189.

FLIKE, U. Introdução à pesquisa qualitativa. Trad. Joice Elias Costa. 3. ed. Porto Alegre: Artmed, 2008.

FOUCAUlT, M. Aula de 17 de março de 1976. In: FOUCAULT, M. Em defesa da sociedade: o curso no Collège de France (19751976). São Paulo: Martins Fontes, 1999. p. 285-315.

FOUCAULT, M. História da sexualidade: o uso dos prazeres. Rio de Janeiro: Paz e Terra, 2012.

FÉLIX, J; COSTA, E. G1, Boa vista, 19. ago. 2018. Após ataques de brasileiros, 1.2 mil venezuelanos deixara o Brasil, diz Exército.

Disponível em: https://www.facebook.com/search/posts/?q=refugiados\%20venezuelanos\%20expulsos.\&epa=FILTERS\&filters=eyJycF9hdXRob3 IiOiJ7XCJuYW11XCI6XC JhdXRob3JcIixcImFyZ3NcIjpcIjE4MDU2Mjg4NTMyOTEzOFwifSJ9. Acesso em: 23 jul. 2019.

GEE, J. Situated Language and Learning. A critique of traditional shooling. New York: Routledge, 2004.

GROSFOGUEL, R. Para descolonizar os estudos da economia política e os estudos pós-coloniais: Transmodernidade, pensamento de fronteira e colonialidade global. Revista Crítica de Ciências Sociais, n. 80, p. 115-147, mar. 2008.

ONU. Qual a diferença entre 'refugiados' e 'migrantes'?. 2016. Disponível em: https://nacoesunidas.org/qual-a-diferenca-entrerefugiados-migrantes/. Acesso em: 13 jul. 2019.

PENNYCOOK, A. Global Englishes and transcultural flows. London: Routledge, 2007. 
PINTO, J. P.; AMARAL, D. Corpos em trânsito e trajetórias textuais. Revista da Anpoll, n. 40, p. 151-164, jan./jun. 2016.

SILVA, D. N. Investigating violence in language: an introduction. In: SILVA, D. N. Language and violence: pragmatic perspectives (org.). Amsterdan: John Benjamins Publishing Company, 2017. p. 1-28.

SILVA, D. N. Pragmática da violência: o nordeste na mídia brasileira. Rio de Janeiro: 7 Letras, 2012.

SILVA, D. C. P. (Meta)pragmática da violência linguística: patologização de vidas trans em comentários online. Trabalhos em Linguística Aplicada, v. 58, n. 2, p. 957-985, maio/ago, 2019a.

SILVA, D. C. P. O dispositivo da colonialidade de gênero no discurso transfóbico online. Raído, v. 13, n. 33, p. 28-54, jul./dez. $2019 b$.

SILVA, D. C. P. Quando dizer é violentar: violência linguística e transfobia em comentários online. Salvador: Devires, 2019c.

SILVESTREIN, M. Indexical order and dialetics of sociolinguistics life. Lenguage \& Comunication, v. 23, n. 3-4, p. 193-229, 2003.

SZUNDY, P.; FABRÍCIO, B. F. Linguística Aplicada e indisciplinaridade no Brasil: promovendo diálogos, dissipando brumas e projetando desafios epistemológicos. In: SZUNDY, P. T. C.; TILIO, R.; MELO, G. C. V. (org.). Inovações e desafios epistemológicos em Linguística Aplicada: perspectivas sul-americanas. São Paulo: Pontes, 2019. p. 229-260.

VENEZUELANOS EXPULSOS DO BRASIL, 2019. Disponível em: https://www.youtube.com/watch?v=DNpJNT50alc. Acesso em: 24 jul. 2019.

\section{()(1) $\odot$}

